CTT; 78 (25\%) had consolidation and 274 (88\%) had PE (figure 1). Patients from Asian, Black and Other ethnic minority groups had a higher prevalence and severity of multifocal ground glass changes on CTT compared to those from White groups (severe ground glass changes for White: 15 [6\%]. Asian: 6 [14\%], Black 2 [11\%], Other 8 [47\%], $p<0.001)$. After one year, 104 (33\%) patients died. On univariable analysis, multifocal ground glass changes and consolidation were related to all-cause mortality at one year. In a model consisting of age; ethnicity; gender; number of comorbidities; admission National Early Warning Score-2; admission lymphocyte count; C-reactive protein and urea, the addition of worsening ground glass changes on CTT were related to all-cause mortality at one year (aHR: 1.29, 95\% CI 1.08-1.55, $p=0.005$ and Figure) and boosted the model's cumulative discrimination (Harrell's c statistic 0.75 from $0.69, p<0.001$ ).

Conclusion Evidence of COVID-19 pneumonia on CTT is more common and severe in patients from ethnic minority groups and is independently associated with worse prognosis following hospitalisation.

\section{P131 THE DEGREE OF ACUTE RESPIRATORY SUPPORT WITH COVID-19 PNEUMONIA, SMOKING STATUS ON ADMISSION AND NON-RESOLVING CT FEATURES AT THREE MONTHS- ARE THERE LINKS?}

H Karimzadeh, R Penfold, U Nnajiuba, A Wight. Wirral Lung Unit, Wirral University Teaching Hospital NHS Foundation Trust, Birkenhead, UK

\subsection{6/thorax-2021-BTSabstracts.240}

Introduction and Objectives BTS guidelines suggest radiological follow up at 12 weeks for patients with COVID-19 associated pneumonia. It is suggested development of post-covid fibrotic changes is more prevalent with severity of illness. ${ }^{1}$ We compared illness severity based on maximal respiratory support with non-resolving changes on CT imaging at $>12$ weeks. Smoking status at time of admission was also collected.

Methods Retrospective analysis of COVID-19 patients surviving to follow up identified either by CVCX1 coded CXR or CVCX2 coded CXR and positive PCR between March 2020January 2021. This identified 912 patients reviewed at 12 weeks with CXR \pm CT imaging. 50/912 patients (5.5\%) had evidence of either established fibrotic change or ongoing pneumonitis on CT. Imaging was reviewed by radiologist using suggested scoring system for Covid-19 follow-up 2 based on sum of $0-5$ severity in 5 lobes (total 0-25) for markers of fibrosis/pneumonitis.

Results Comparison is shown in table 1. All patients requiring more than $60 \%$ oxygen therapy received advanced respiratory support. $10 / 50$ patients $(20 \%)$ required no supplementary oxygen and 6/10 were not admitted to hospital. Comparison mean fibrosis score; IPPV-18.6, CPAP/HFNO-9.23, RA- 8.5. There were no current smokers in the follow-up cohort, 24 ex-smokers.

Conclusions We noted significant risk for developing postCovid pneumonic fibrotic changes even in clinically mild cases. With $\mathrm{SpO} 2$ at times of peak incidence being main indicator for CXR and/or admission we surmise there may be a significant unrecognized population without an initial CXR to prompt follow-up. It is not clear whether these patients will develop significant symptoms to prompt future investigations and what impact this might have. No patients developing

\begin{tabular}{|c|c|c|c|c|c|}
\hline Max Fi02/Resp support & $21 \%$ & $\begin{array}{l}\leq \\
35 \%\end{array}$ & $\begin{array}{l}40 \% \leq \\
60 \%\end{array}$ & $\begin{array}{l}\text { CPAPI } \\
\text { HFNO }\end{array}$ & IPPV \\
\hline No. patients & 10 & 8 & 11 & 16 & 5 \\
\hline Age (mean) & 62.1 & 71.6 & 62.5 & 62.7 & 51.6 \\
\hline Mean fibrosis score $(0-25)$ & 8.5 & 7.0 & 11.6 & 9.23 & 18.6 \\
\hline $\begin{array}{l}\text { Mean pneumonitis score (0- } \\
25)\end{array}$ & 6.7 & 9.6 & 7.5 & 15.2 & 22.6 \\
\hline M: F ratio & $7: 3$ & $3: 5$ & $6: 5$ & $10: 6$ & $4: 1$ \\
\hline Ex-smokers*\% & 50 & 75 & 64 & 33 & 20 \\
\hline Current smokers* & 0 & 0 & 0 & 0 & 0 \\
\hline
\end{tabular}

ongoing CT changes were current smokers- a topic we suggest for further study and correlation.

\section{REFERENCES}

1. McGroder CF, et al. Pulmonary fibrosis 4 months after COVID-19 is associated with severity of illness and blood leucocyte telomere length. Thorax 29 April 2021. doi:10.1136/thoraxjn-2021-217031

2. Xiaoyu Han, et al. Six-month follow-up chest CT findings after severe COVID-19 pneumonia. Radiology 2021;299:1, E177-E186.

\section{P132 INTERMEDIATE FOLLOW UP OF RADIOLOGICAL INTERSTITIAL CHANGES FOR COVID-19 PATIENTS OVER THE FIRST YEAR POST DISCHARGE: A LONGITUDINAL STUDY}

JC Gates, A Draper, J Moser, J Arberry, D Jajbhay, J Panaguiton, E Yarham, YE Ong, R Aul. St George's Hospital, London, UK

\subsection{6/thorax-2021-BTSabstracts.241}

Introduction COVID-19 follow up has become a high priority, with clear evidence that significant proportions of survivors continue to have symptoms at follow up. It has been demonstrated that $56 \%$ of those with severe COVID had lung diffusion (DLCO) impairment and more than $50 \%$ had radiographic abnormalities at 6 month follow up. ${ }^{1}$ However there is limited evidence at present how these abnormalities change over time beyond the first assessment.

We present CT imaging results for patients discharged after COVID-19 infection, at various time points over the first year after discharge. Pulmonary function tests for this cohort are currently being analysed.

Methods 387 COVID-19 patients were followed up post discharge. There are 81 baseline CTs available for analysis, and of these 35 had a repeat CT thorax prior to second assessment based on clinical need.

All the CT images were independently assessed by a Thoracic Radiologist using BSTI criteria ${ }^{2}$ and compared to subsequent CTs for the same patient. A higher proportion of those with PCVCT3 had repeat CT imaging as expected due to clinical need.

Discussion On repeat assessment, all patients had significantly improved respiratory symptom scores (MRC and CAT score). Only 3 of 35 patients had progressive fibrosis on the second scan, all of whom had PCVCT3 on initial imaging. None of those who had PCVCT1 or 2 on initial imaging went on to develop fibrosis and all showed improvement on subsequent imaging. 
Abstract P132 Table 1 Follow up symptoms and radiological findings at first and second assessment post discharge. Analysed by Wilcoxon Rank Sum, median (range)

\begin{tabular}{llll}
\hline & $\begin{array}{l}\text { First } \\
\text { timepoint }\end{array}$ & $\begin{array}{l}\text { Second } \\
\text { timepoint }\end{array}$ & P value \\
\hline Clinic assessment (months post discharge) & $1.5(1-3)$ & $9(6-12)$ & \\
CT scan (months post discharge) & $2.5(1-4)$ & $8(6-12)$ & \\
MRC score & $3(2-4)$ & $1(1-3)$ & $<0.0001$ \\
CAT score & $12(7-18)$ & $6(4-14)$ & 0.002 \\
Numbers of CT performed & 81 & 35 & \\
Numbers of CTs performed for isolated ground & 47 & 13 & \\
glass abnormalities (PCVCT1+2) & & & \\
Numbers of CTs performed for fibrosis plus & 34 & 22 & \\
ground glass changes (PCVCT3) & & & \\
\hline
\end{tabular}

Conclusion Those patients found to have PCVCT3 changes on initial CT should receive long term follow up as a proportion (approximately 9\%) of them may develop progressive fibrotic changes. However this is likely to only represent less than $1 \%$ of all COVID-19 patients discharged from hospital. Longer term follow up is needed to determine the ongoing trajectory of these interstitial changes. These patients may potentially benefit from clinical trials in the future for the use of antifibrotics.

\section{REFERENCES}

1. Huang $C$, et al. 6-month consequences of COVID-19 in patients discharged from hospital: a cohort study. Lancet 2021:397:220-32.

2. BSTI. BSTI Post-COVID-19 CT Report Codes. BSTI 22-May-2020.

\section{P133 MEASURING OXYGEN SATURATION ON FOLLOW UP CHEST X-RAY AND RESOLUTION OF RADIOLOGICAL CHANGES AT 6 TO 12 WEEKS POST COVID PNEUMONITIS}

A Anwar, E Tubman, W McLean, M Ingram, J Scott-Taggart, C Alexander. Royal Surrey Hospital NHS Foundation Trust, Guildford, UK

\subsection{6/thorax-2021-BTSabstracts.242}

Introduction Recovery course post COVID-19 pneumonia remains poorly understood. This study aims to present data on clinical and radiological characteristics of COVID-19 patients admitted to the hospital, as well as their follow-up after discharge. Data collected before any official guidelines however it was in line with subsequent models recommended by the British Thoracic Society. ${ }^{1}$

Methods The study included all COVID-19 patients admitted between mid-March and September 2020 with chest X-Ray (CXR) changes consistent with COVID pneumonitis. Patients had a virtual respiratory clinic review, with a repeat CXR and oxygen saturation (SpO2), 6 to 12 weeks after discharge. Radiographers were trained in a novel role to measure $\mathrm{SpO} 2$ (with target $\mathrm{SpO} 2$ and local escalation policy).

Results 302 patients were admitted with COVID during the study period, of these 207 (68.5\%) had radiological changes consistent with COVID pneumonitis. Ethnicity data was available for 110 (53\%) patients. 86\% of patients were Caucasians while $14 \%$ patients were of Black, Asian and minority ethnic (BAME) background. The median length of stay in the hospital was 8 days (IQR: 13). Smoking status was recorded for 97
Abstract P133 Table 1 Characteristics and outcome of patients with COVID-19 on admission and follow up

\begin{tabular}{|c|c|c|c|c|c|}
\hline & $\mathrm{N}$ & Males & Females & $\begin{array}{l}\text { Mean age } \\
\text { (years) }\end{array}$ & SD \\
\hline Total admitted patients* & 302 & 165 & 137 & 64 & 20.65 \\
\hline $\begin{array}{l}\text { - Patients with abnormal CXR on } \\
\text { admission }\end{array}$ & 207 & 124 & 83 & 67.5 & 16.74 \\
\hline $\begin{array}{l}\text { - Patients with normal CXR on } \\
\text { admission }\end{array}$ & 73 & 31 & 42 & 62.9 & 20.71 \\
\hline $\begin{array}{l}\text { - No CXR available at admission } \\
\text { Follow up CXR** }\end{array}$ & 22 & 10 & 12 & 65 & 22.42 \\
\hline - Follow up CXR done & 155 & 93 & 62 & 65 & 24 \\
\hline $\begin{array}{l}\text { - Follow up CXR normal/baseline } \\
\text { changes }\end{array}$ & 122 & 70 & 52 & 62.7 & 15.8 \\
\hline - Follow up CXR abnormal & 33 & 23 & 10 & 68.3 & 13.6 \\
\hline
\end{tabular}

(46\%) patients. 54 out of 97 (55\%) had a history of smoking. $79 \%$ of patients had normal follow-up CXR. $33(21 \%)$ patients had persistent abnormalities including residual infiltrates, atelectasis, pleural effusion and fibrotic changes. Patients with normal follow-up CXR were younger than those with persistent changes $(\mathrm{p}<0.05)$. SpO2 was checked for 95 out of 155 patients (61\%). At the time of follow-up CXR, 92 patients had $\mathrm{SpO} 2>92 \%$ while 3 patients were found to have $\mathrm{SpO} 2<92 \%$. The virtual screening clinic appointment take-up rate was $83 \%(\mathrm{~N}: 129)$.

Conclusion Our data shows that the majority of patients with COVID pneumonitis had a normal CXR at 6-12 weeks post discharge. However, a significant proportion of patients still have on-going radiological changes. There was no correlation between target $\mathrm{SpO} 2$ and ongoing radiological changes. Patients with normal follow-up CXR were significantly younger than those with persistent changes. We continue to study this group of patients and post COVID sequelae.

\section{REFERENCE}

1. https://www.brit-thoracic.org.uk/covid-19/covid-19-information-for-the-respiratorycommunity/

\section{P134 HEALTH DEPRIVATION AND POST-COVID FIBROSIS: IS THERE A RELATIONSHIP AND WHAT IS THE LONG-TERM IMPACT?}

R Penfold, H Karimzadeh, U Nnajiuba, A Wight. Wirral University Teaching Hospital, Wirral, UK

\subsection{6/thorax-2021-BTSabstracts.243}

Introduction and Objectives Health inequalities are associated with worse outcomes of COVID-19 illness. ${ }^{1}$ Health deprivation and disability is one domain within the Index of Multiple Deprivation (IMD). We investigated potential correlation between health deprivation and development of new fibrosis in COVID-19 survivors within a mixed catchment area in NW England in which 35\% of neighbourhoods are within the $10 \%$ most deprived decile for health and disability.

Methods Retrospective analysis of patients identified between March 2020 and January 2021 with either CVCX1 coded 